\title{
Building Information Modeling (BIM): Now and Beyond
}

\author{
Salman Azhar, (Auburn University, USA) \\ Malik Khalfan and Tayyab Maqsood, (RMIT University, Australia)
}

\begin{abstract}
Building Information Modeling (BIM), also called n-D Modeling or Virtual Prototyping Technology, is a revolutionary development that is quickly reshaping the ArchitectureEngineering-Construction (AEC) industry. BIM is both a technology and a process. The technology component of BIM helps project stakeholders to visualize what is to be built in a simulated environment to identify any potential design, construction or operational issues. The process component enables close collaboration and encourages integration of the roles of all stakeholders on a project. The paper presents an overview of BIM with focus on its core concepts, applications in the project life cycle and benefits for project stakeholders with the help of case studies. The paper also elaborates risks and barriers to BIM implementation and future trends.
\end{abstract}

Keywords: Building Information Modeling (BIM), n-D Modeling, Collaboration, Integrated Project Delivery (IPD), Information Technology, Project Management

\section{Introduction}

Building Information Modeling (BIM) is a revolutionary technology and process that has quickly transformed the way buildings are conceived, designed, constructed and operated (Hardin, 2009). Although the roots of BIM can be traced back to the parametric modeling research conducted in USA and Europe in late 1970s and early 1980s, the ArchitectureEngineering-Construction (AEC) industry practically started to implement it in projects from the mid-2000s. During the last seven years, the term BIM has gone from being a buzzword to the centerpiece of AEC technology (Khemlani, in Eastman et al., 2011).

The National Building Information Modeling Standards (NBIMS) committee of USA defines BIM as follows: "BIM is a digital representation of physical and functional characteristics of a facility. A BIM is a shared knowledge resource for information about a facility forming a reliable basis for decisions during its life cycle; defined as existing from earliest conception to demolition. A basic premise of BIM is collaboration by different stakeholders at different phases of the life cycle of a facility to insert, extract, update or modify information in the BIM to support and reflect the roles of that stakeholder (NBIMS, 2010)."

The Associated General Contractors of America (AGC) perceived BIM as: "Building Information Modeling is the development and use of a computer software model to simulate the construction and operation of a facility. The resulting model, a Building Information Model, is a data-rich, object-oriented, intelligent and parametric digital representation of the facility, from which views and data appropriate to various users' needs can be extracted and analyzed to generate information that can be used to make decisions and improve the process of delivering the facility (AGC, 2005)."

As is clear from the above two definitions that BIM is not just software; it is a process and software. BIM means not only using three-dimensional intelligent models but also making significant changes in the workflow and project delivery processes (Hardin, 2009). BIM represents a new paradigm within $\mathrm{AEC}$, one that encourages integration of the roles of all stakeholders on a project. It has the potential to promote greater efficiency and harmony 
among players who, in the past, saw themselves as adversaries (Azhar et al., 2008a). BIM also supports the concept of Integrated Project Delivery (IPD) which is a novel project delivery approach to integrate people, systems, business structures and practices into a collaborative process to reduce waste and optimize efficiency through all phases of the project life cycle (Glick and Guggemos, 2009).

The purpose of this paper is to provide an overview of BIM concept, applications, benefits, risks and associated challenges to the AEC industry. In the following section, the BIM concept is discussed from technology and process standpoints. After that, the BIM applications in the project life cycle - programming, design, preconstruction, construction and post-construction - are discussed. This is followed by discussion on BIM benefits for project stakeholders namely owners, designers, constructors and facility managers. After that, BIM risks and barriers to implementation in the AEC industry are elaborated. At the end, the future of BIM is examined and conclusions are drawn.

\section{Understanding BIM}

\section{BIM as a Technology}

From technology perspective, a building information model is a project simulation consisting of the 3D models of the project components with links to all the required information connected with the project planning, design, construction or operation as depicted in Figure 1 (Kymmell, 2008). The BIM technology hailed from the object-oriented parametric modeling technique (Azhar et al., 2008b). The term "parametric" describes a process by which an element is modified and an adjacent element or assembly (e.g. a door attached to a wall) is automatically adjusted to maintain a previously established relationship (Stine, 2011).

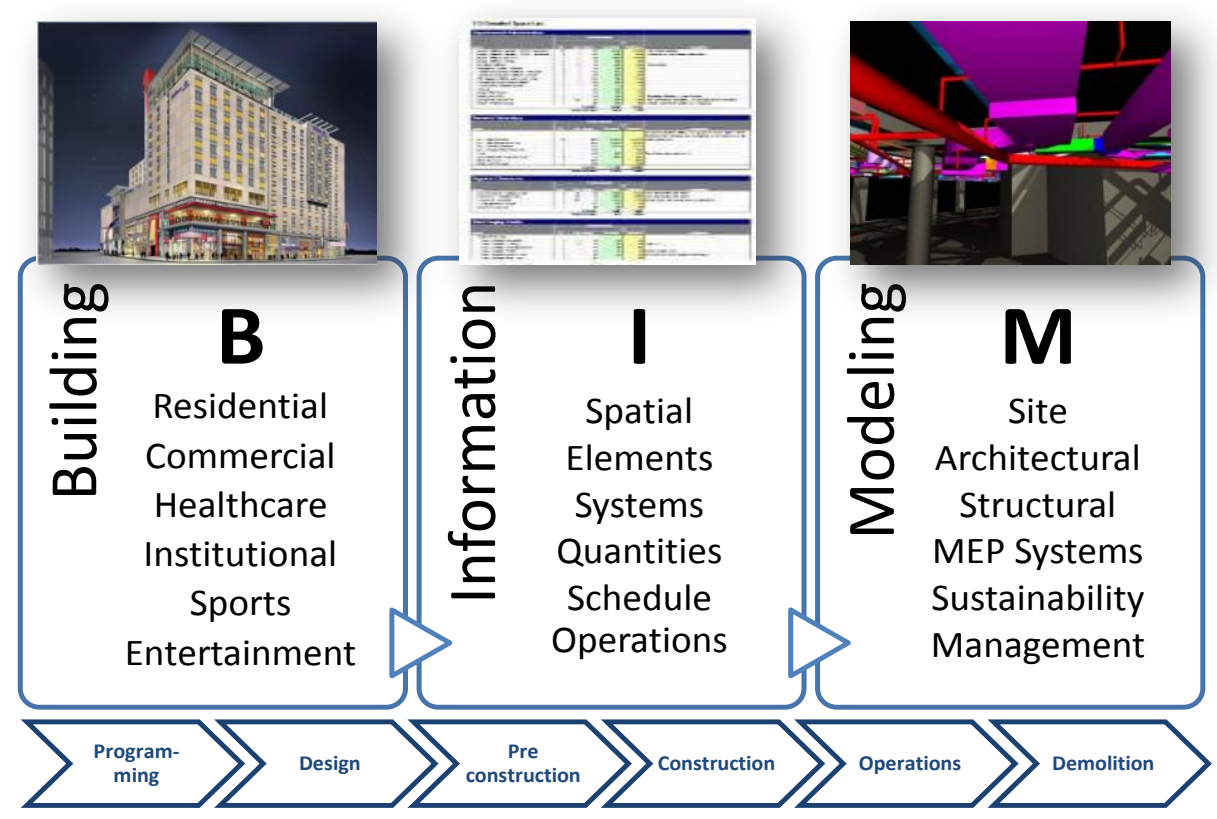

Figure 1 A Visual Representation of BIM Concept

The principal difference between BIM technology and conventional 3D CAD is that the latter describes a building by independent $3 \mathrm{D}$ views such as plans, sections and elevations. Editing one of these views requires that all other views must be checked and updated, an error-prone process that is one of the major causes of poor documentation. In addition, data in these 3D drawings are graphical entities only, such as lines, arcs and circles, in contrast to the intelligent contextual semantic of BIM models, where objects are defined in terms of building elements and systems such as spaces, walls, beams and columns. A building

Azhar, S et al. (2012) 'Building information modeling (BIM): now and beyond', Australasian Journal of Construction Economics and Building, 12 (4) 15-28 
information model carries all information related to the building, including its physical and functional characteristics and project life cycle information, in a series of "smart objects". For example, an air conditioning unit within a BIM would also contain data about its supplier, operation and maintenance procedures, flow rates and clearance requirements (Azhar and Richter, 2009; CRC Construction Innovation, 2007).

Eastman et al. (2011) indicated that the following types of digital models do not fall under the category of BIM: (1) models that contain 3D data only and no object attributes (i.e. missing "i" of BIM) ; (2) models with no support of behavior; (3) models that are composed of multiple 2D CAD reference files that must be combined to define the building; and (4) models that allow changes to dimensions in one view that are not automatically reflected in other views.

\section{BIM as a Process}

BIM can be viewed as a virtual process that encompasses all aspects, disciplines, and systems of a facility within a single, virtual model, allowing all team members (owners, architects, engineers, contractors, subcontractors and suppliers) to collaborate more accurately and efficiently than traditional processes. As the model is being created, team members are constantly refining and adjusting their portions according to project specifications and design changes to ensure the model is as accurate as possible before the project physically breaks ground (Carmona and Irwin, 2007). The foundations of BIM are laid on two pillars, communication and collaboration. The successful implementation of BIM requires early involvement of all project stakeholders. It means that the traditional project delivery systems (e.g. design-bid-build) have very limited role in BIM-based projects. Recently the Integrated Project Delivery (IPD) concept emerges as a natural companion to BIM. IPD brings key construction management, trades, fabrication, supplier and product manufacturer expertise together with design professionals and the owner earlier in the process to produce a design that is optimized for quality, aesthetics, constructability, affordability, timeliness and seamless flow into lifecycle management. In the United States, the IPD has become a preferred project delivery system for all major projects involving BIM (McGraw-Hill Construction, 2008). Figure 2 illustrates the difference between "traditional" and "BIM" process.
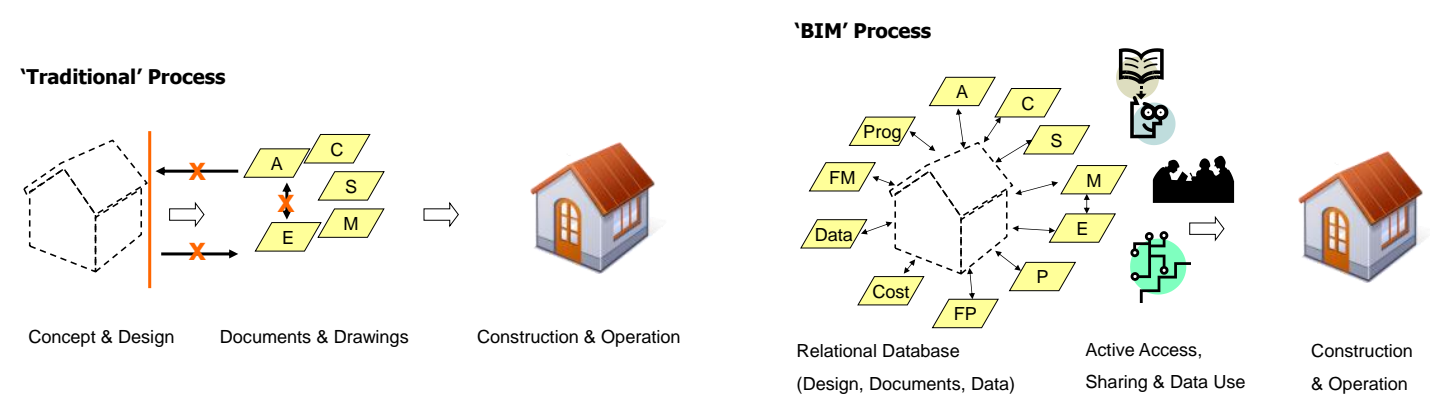

Figure 2 A Comparison between "Traditional" and "BIM" Process

(Courtesy of: Holder Construction, Atlanta, Georgia, USA)

\section{BIM Applications in the Project Life Cycle}

BIM applications spans over the entire life cycle of a facility. This section presents a brief overview of important BIM applications in the project programming, design, preconstruction, construction, and post-construction (operations and maintenance) phases.

\section{BIM and Project Programming}

The use of BIM in the project programming phase allows project team to analyze space and understand the complexity of space standards and land regulations, which saves time and provide the team with opportunity of doing more value-added activities (CICRP, 2009). 
Recently, some researchers have investigated the integration of BIM with GIS (Geographical Information Systems) which can aid project planners in selecting appropriate site and conducting project feasibility and marketing studies (Berlo and Laat, 2011; Isikdag et al., 2008). Following are some of the benefits of 'GIS-BIM' based site analysis (CICRP, 2009):

- Aid in determining if potential sites meet the required criteria according to project requirements, technical and financial factors, etc.

- Decrease costs of utility demand and demolition.

- Minimize risk of hazardous materials.

The advances and economy of 3D laser scanning equipment has allowed practitioners to accurately scan existing utilities and integrate them in the BIM model as show in Figure 3 . In addition, 3D laser scanning can be used to scan and accurately (within industry tolerances) develop BIM models of existing facilities which can be later used for renovation and adaptive re-use of existing buildings.

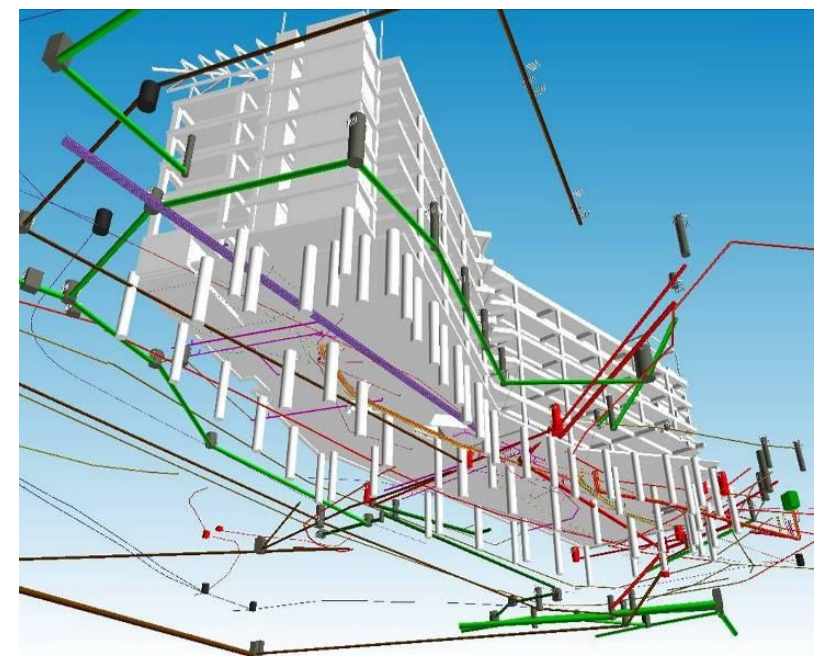

Figure 3 Utilization of BIM Model for Underground Utilities Coordination (Courtesy of: Holder Construction, Atlanta, Georgia, USA)

\section{BIM and Project Design}

The architects and engineers can take advantage of BIM applications at different stages of project design namely schematic design (SD), detailed design (DD) and construction detailing (CD). Table 1 illustrates specific BIM applications in each stage of project design.

\begin{tabular}{|c|c|c|}
\hline Schematic design & Detailed design & Construction Detailing \\
\hline $\begin{array}{l}\text { - Options Analysis (to } \\
\text { compare multiple design } \\
\text { options) } \\
\text { - Photo Montage (to } \\
\text { integrate photo realistic } \\
\text { images of project with its } \\
\text { existing conditions) }\end{array}$ & $\begin{array}{l}\text { - } 3 D \text { exterior and interior models } \\
\text { - Walk-through and fly-through } \\
\text { animations } \\
\text { - Building performance analyses } \\
\text { (e.g. energy modeling) } \\
\text { - Structural analysis and design }\end{array}$ & $\begin{array}{l}\text { - } 4 \text { D phasing and scheduling } \\
\text { - Building systems analysis } \\
\text { (e.g. clash detections) } \\
\text { - Shop or fabrication drawings }\end{array}$ \\
\hline
\end{tabular}

Table 1 BIM applications in project design phase

Case study 1 (Azhar, 2011)

This case study illustrates the use of BIM in the schematic design phase. The Options Analysis was performed for selecting the most economical and workable building layout. The

Azhar, S et al. (2012) 'Building information modeling (BIM): now and beyond', Australasian Journal of Construction Economics and Building, 12 (4) 15-28 
project is a higher education facility at Savannah State University, Savannah, Georgia, USA. For this project, the general contractor coordinated with the architect and the owner at the schematic design phase to prepare building information models of three different design options. For each option, the BIM-based cost estimates were also prepared using three different cost scenarios (budgeted, midrange, and high range), as shown in Figure 3 . The owner was able to walk through all the virtual models to decide the best option that fit his requirements. The entire process took 2 weeks, and the owner achieved roughly $\$ 1,995,000$ cost savings at the schematic design stage by selecting the most economical design option. Although it could be argued that the owner may have reached the same conclusion using traditional drawings, the use of BIM technology helped him make a quick, definitive, and well-informed decision.

\begin{tabular}{|c|c|c|c|c|c|}
\hline Aspect & $\begin{array}{c}\text { Owner's } \\
\text { Requirements }\end{array}$ & Option A & Option B & Option C & $v_{1}$ \\
\hline & & Option A & Option B & Option C & 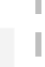 \\
\hline \multicolumn{6}{|l|}{ Front Elevation } \\
\hline Plan & & & & & \\
\hline Stories & Not specified & 2 & 2 & 3 & \\
\hline Cost Scenarios & & & & $\pi$ & ॥ \\
\hline Budget: $\quad \$ 147.74 / \mathrm{sf}$ & $\$ 11,000,000$ & $\$ 12,897,111$ & $\$ 12,270,91 \mathrm{c}$ & $\$ 10,910,894$ & ॥ \\
\hline Mid-Range: $\$ 175.00 / \mathrm{sf}$ & $\$ 13,030,325$ & $\$ 15,276,800$ & $\$ 14,535,14 \mathrm{C}$ & $\$ 12,924,100$ & I \\
\hline High-Range: $\$ 200.00 / \mathrm{sf}$ & $\$ 14,891,800$ & $\$ 17,459,200$ & $\$ 16,611,60 c$ & $\$ 14,770,400$ & 1 \\
\hline
\end{tabular}

Figure 3 Options Analysis for the Savannah State Academic Building (Courtesy of: Holder Construction Company, Atlanta, GA)

\section{BIM in the Preconstruction Phase}

The applications of BIM in the preconstruction phase can be summarized as follows:

- Estimating: From building information models, the contractors can perform fairly accurate quantity survey and prepare detailed estimates. Based on the data of 32 major projects, the Stanford University's Center for Integrated Facilities Engineering (CIFE) reported that the accuracy of BIM-based estimates was within $3 \%$ with up to $80 \%$ time reduction in generating these estimates (cited by CRC Construction Innovation, 2007).

- Site coordination: Using 3D or 4D site coordination models, the contractors can plan for site logistics, develop traffic layouts, and identify potential hazards at the jobsite which can aid in preparing a more realistic site safety plan.

- Constructability analysis: Using BIM models, the project team can perform detailed constructability analysis to plan sequence of operations at the jobsite.

\section{Case study 2}

This case study illustrates the use of BIM for safety planning and management. The project is Wellness Center Building at the campus of Auburn University, Auburn, Alabama which is currently under construction and planned to complete by April 2013. The project team developed the BIM model of the facility in the project design phase and uses it for site coordination and constructability analysis. Through coordinated meetings involving project managers, site superintendents, and subcontractors, all possible major and minor site 
hazards are identified and appropriate mitigation plans are developed (see Figure 4). The relevant 4D animations are also used in the tool box meetings to illustrate daily construction activities to the workers. So far, no major or minor accident is reported at the site. The site superintendents rated BIM as "... a great tool for educating workers in quick time about the site hazards” (Azhar et al., 2012).

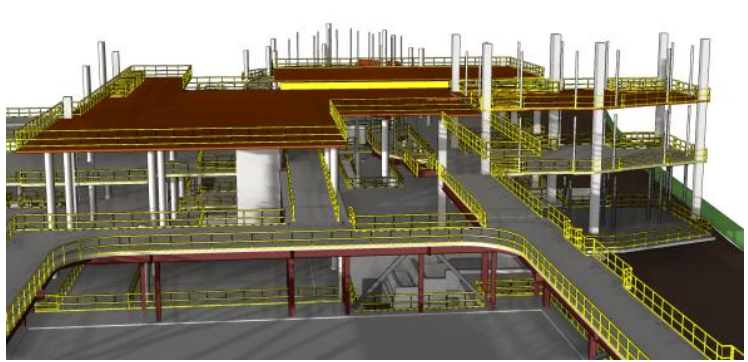

(a) Fall protection railings

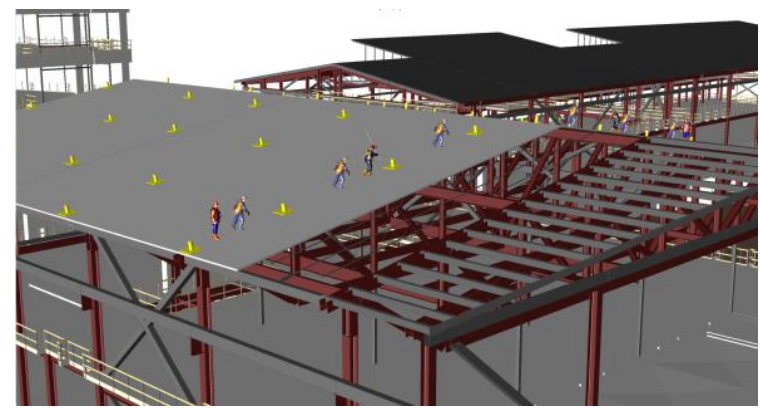

(b) Fall protection plan for roof workers

Figure 4 A BIM-based site specific safety plan (Azhar et al., 2012)

\section{BIM in the Construction Phase}

In the construction phase, the project team can use BIM for the following activities: (1) Project progress monitoring using 4D phasing plans; (2) For trade coordination meetings (see Figure 5); and (3) Integrating RFIs, change orders and punch list information in the BIM models. Throughout the construction period, the project team must continuously update the BIM model so that it reflects the most up-to-date information which later on can be used by the facility managers for building operations and maintenance.

The advances in smartphone and tablets technology have allowed contractors and subcontractors to frequently use BIM models at the jobsite for information extraction and coordination. Some of the notable BIM apps include BIMX ${ }^{\circledR}$, Bentley Navigator ${ }^{\circledR}$, Buzzsaw $^{\circledR}$, etc. Recently the Autodesk ${ }^{\circledR}$ has started a Cloud-based service, The Autodesk $360^{\odot}$, which allows users to share BIM models in a web environment and perform various tasks in the field such as walk-throughs, clash detection and preparing digital RFIs (Rubenstone, 2012).

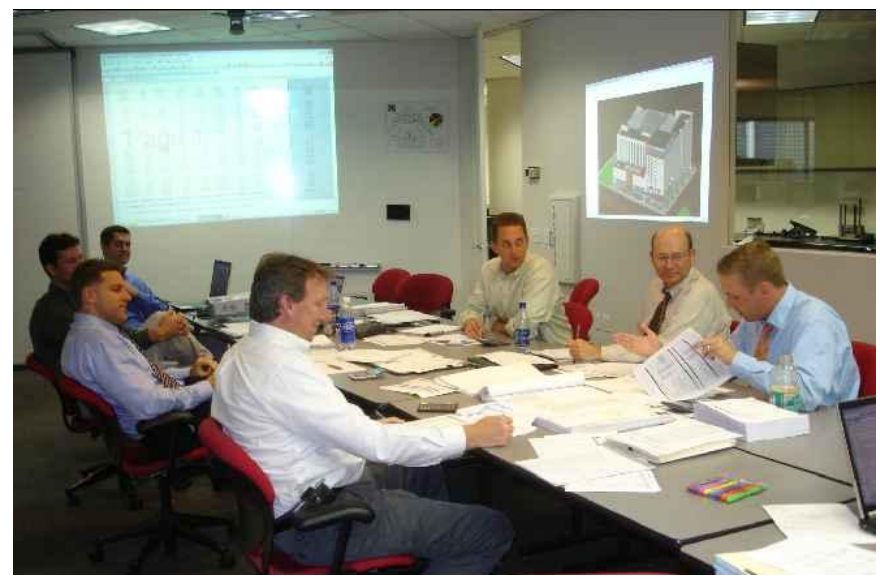

Figure 5 Trade coordination meeting using BIM in a job trailer (Courtesy of: Holder Construction Company, Atlanta, GA) 


\section{BIM in the Post construction Phase}

A building information model contains complete information about a facility as it evolves through planning, design and construction. This information can be leveraged for downstream use by facility managers thereby making operations and maintenance of a facility more efficient. Research suggests that $85 \%$ of the lifecycle cost of a facility occurs after construction is completed and approximately $\$ 10$ billion are annually lost in the U.S. alone due to inadequate information access and interoperability issues during operations and maintenance phases (Newton, 2004). The use of BIM for facility management (FM) can significantly help to prevent these loses.

The fundamental benefit of a BIM model is that it provides information about a building and its spaces, systems and components. The overall goal is to transfer these data into facility management operations. In this manner information about building systems and equipment can be accessed by simply clicking on an object in a BIM model. For example, the information that is extracted for a piece of equipment such as a VAV box are location, name, model number, product type, operation and maintenance manuals, commissioning information and performance data. This makes it very simple for a maintenance worker to access the required information vital to different systems in the building as shown in Figure 6 (Philips and Azhar, 2011).

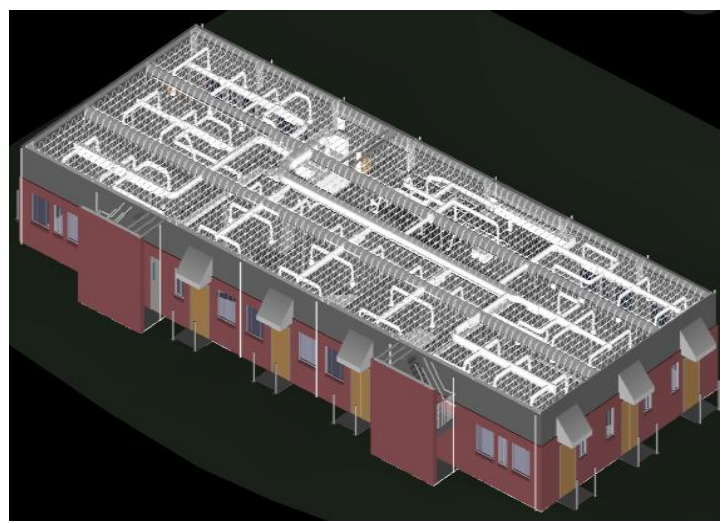

(a) A HVAC Model

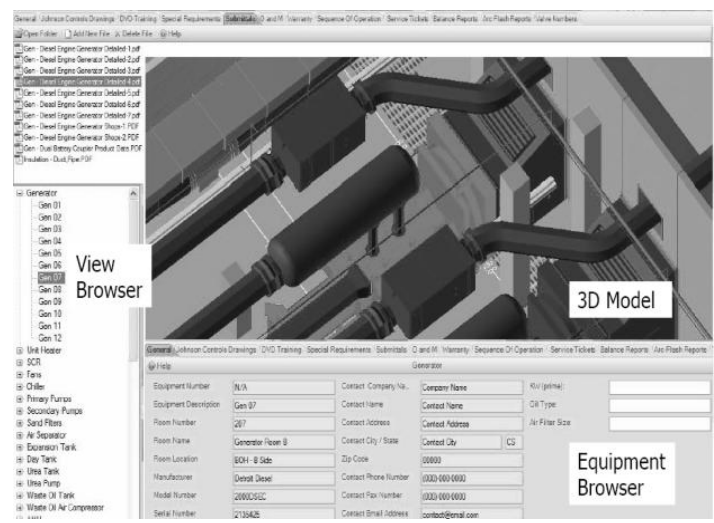

(b) Data of HVAC Equipment

Figure 6 IIIustration of use of BIM in facility operations

Following are some additional applications of BIM for facility operations and management: (1) Maintenance work order management; (2) Emergency service request management; (3) Space planning and management; (4) Inventory management and inspections; (5) Move management; and (6) Real estate portfolio management.

\section{BIM Benefits for Project Stakeholders}

Before discussing benefits of BIM for project owners, designers, constructors and facility managers, it is useful to summarize BIM applications for these stakeholders. Table 2 provides this summary. The individual benefits of BIM for each stakeholder are discussed in the following sections.

\section{Project Owners}

Owners can achieve significant benefits on projects where BIM technology and processes are applied. Eastman et al. (2011) and Reddy (2011) summarized the following benefits of BIM for project owners: (1) Early design assessment to ensure project requirements are met; (2) Operations simulation to evaluate building performance and maintainability; (3) Low financial risk because of reliable cost estimates and reduced number of change orders; (4) Better marketing of project by making effective use of 3D renderings and walk-though

Azhar, S et al. (2012) 'Building information modeling (BIM): now and beyond', Australasian Journal of Construction Economics and Building, 12 (4) 15-28 
animations; and (5) Complete information about building and its systems in a single file. Due to these and other tangible and intangible benefits of BIM, large project owners in the USA (such as the General Services Administration (GSA), the U.S. Army Corp of Engineers (USACE), etc.) are increasingly requiring designers and contractors to utilize BIM in all projects (Ku and Taiebat, 2011).

\begin{tabular}{|l|c|c|c|c|}
\hline \multicolumn{1}{|c|}{ BIM Application } & Owners & Designers & Constructors & $\begin{array}{c}\text { Facility } \\
\text { Managers }\end{array}$ \\
\hline Visualization & $\mathrm{x}$ & $\mathrm{x}$ & $\mathrm{x}$ & $\mathrm{x}$ \\
\hline Options analysis & $\mathrm{x}$ & $\mathrm{x}$ & $\mathrm{x}$ & \\
\hline Sustainability analyses & $\mathrm{x}$ & $\mathrm{x}$ & & \\
\hline Quantity Survey & & $\mathrm{x}$ & $\mathrm{x}$ & \\
\hline Cost Estimation & $\mathrm{x}$ & $\mathrm{x}$ & $\mathrm{x}$ & \\
\hline Site Logistics & $\mathrm{x}$ & & $\mathrm{x}$ & \\
\hline Phasing and 4D scheduling & & $\mathrm{x}$ & $\mathrm{x}$ & \\
\hline Constructability analysis & & $\mathrm{x}$ & $\mathrm{x}$ & \\
\hline Building performance analysis & $\mathrm{x}$ & $\mathrm{x}$ & $\mathrm{x}$ & $\mathrm{x}$ \\
\hline Building management & $\mathrm{x}$ & & & $\mathrm{x}$ \\
\hline
\end{tabular}

Table 2 BIM applications for project stakeholders

\section{Project Designers}

The project architects and engineers can take advantage of BIM in schematic and detailed design; and construction detailing phases as summarized in Table 1. Following are some of the main benefits of BIM for project designers: (1) Better design by rigorously analyzing digital models and visual simulations and receiving more valuable input from project owners; (2) Early incorporation of sustainability features in building design to predicts its environmental performance; (3) Better code compliance via visual and analytical checks; (4) Early forensic analysis to graphically assess potential failures, leaks, evacuation plans and so forth; and (5) Quick production of shop or fabrication drawings (Kymel, 2008).

The early design and preconstruction stages of a building are the most critical phases to make decisions on its sustainability features (Azhar et al., 2009). Traditional Computer-Aided Design (CAD) planning environments typically lack the capability to perform sustainability analyses in the early stages of design development. Building performance analyses are typically performed after the architectural design and construction documents have been produced. This failure to analyze sustainability continually during the design process results in an inefficient process of retroactive modification to the design to achieve a set of performance criteria (Schueter and Thessling, 2008). To assess building performance in the early design and preconstruction phases realistically, access to a comprehensive set of data regarding a building's form, materials, context and systems is required. Since BIM allows for multi-disciplinary information to be superimposed within one model, it creates an opportunity for sustainability measures to be incorporated throughout the design process (Autodesk, 2008). Azhar et al. (2011) found that information for up to 17 LEED $^{\circledR}$ (Leadership in Energy and Environmental Design, a green building rating system used in the USA) credits can be obtained in the design phase by performing BIM-based sustainability analyses. It means a building information model can be used as a by-product for LEED ${ }^{\circledR}$ analysis thereby saving substantial time and resources. 


\section{Project Constructors}

In the United States general contractors are the early adopters of BIM among all stakeholders (Azhar et al., 2008a). The contractors and subcontractors can use BIM for the following applications (Hardin, 2009): (1) Quantity takeoff and cost estimation; (2) Early identification of design errors through clash detections; (3) Construction planning and constructability analysis; (4) Onsite verification, guidance and tracking of construction activities; (5) Offsite prefabrication and modularization; (6) Site safety planning; (7) Value engineering and implementation of lean construction concepts; and (8) Better communication with project owner, designer, subcontractors and workers on site. Through these applications constructors can achieve the following benefits: (1) High profitability; (2) Better customer service; (3) Cost and schedule compression; (4) Better production quality; (5) More informed decision making; and (6) Better safety planning and management.

\section{Case Study 3}

This case study illustrates the use of BIM by general contractor (GC) to minimize design errors via clash detections. The project is a $\$ 35$ million academic building at the campus of Emory University, Atlanta, Georgia, USA. The architectural model was developed by the project architect. The GC acquired 2D structural and MEP systems drawings from project engineers and converted them into 3D BIM models. By integrating all "single" BIM models and through clash detections in the preconstruction phase, the GC was able to rough save $\$ 259,000$ as illustrated in Figure 7.

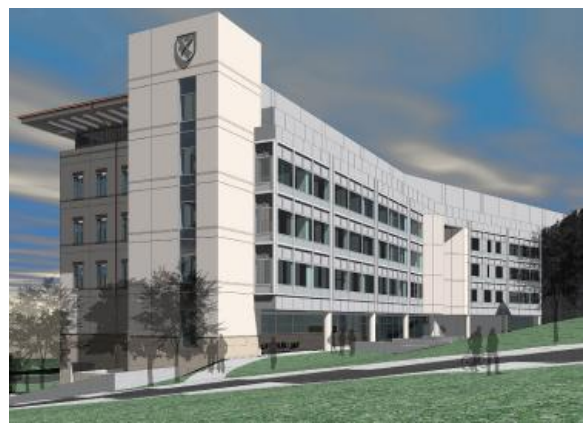

(a) Integrated BIM model

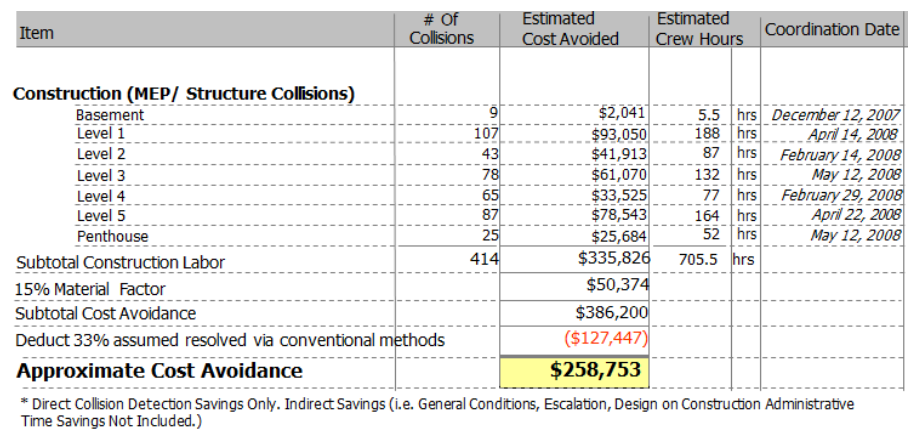

(b) Cost and time savings via clash detections

Figure 7 Use of BIM in the project preconstruction stage (Courtesy of: Holder Construction Company, Atlanta, GA)

\section{Facility Managers}

In the past, facility managers have been handed over the building with boxes and piles of owner's manuals and warranties. The use of BIM provides two major benefits: (1) The same critical information is present in a single electronic file; and (2) the facility managers do not have to sift through the piles of information to gather data. As mentioned by Reddy (2011), "with the BIM database, any information about an equipment is just one-click away." The facility managers can click on any equipment or fixture to obtain information on product, warranties, life cycle of the product, maintenance checks, replacement cost, installation and repair procedures, and even place order for a replacement online (Jordani, 2010). The advances in smart phones and tablet devices (such as iPhone ${ }^{\circledR}$ and iPAD ${ }^{\circledR}$ ) and Augmented Reality (AR) has made it possible to obtain complete information about a building component by just pointing the device towards it. Joyce (2012) reported an AR-based system, InfoSPOT ${ }^{\circledR}$, developed at the Georgia Institute of Technology, Atlanta, Georgia which allows facility managers to obtain quick "on the spot" information about an equipment using their smartphones. 


\section{Risks and Barriers to Implementing BIM}

Besides numerous benefits of BIM for project stakeholders there are many risks and barriers to implement BIM. In other words, BIM is not a panacea for every project and every firm. The BIM related risks can be divided into two broad categories: (1) Technology-related risks; and (2) Process-related risks. Following sections present brief discussion on each category.

\section{Technology-related Risks}

The first technology-related risk is lack of BIM standards for model integration and management by multidisciplinary teams. Integrating multidisciplinary information in a single BIM model requires multiuser access to the BIM model. This requires establishment of protocols in the project programming phase to ensure consistency in information context and formatting styles. At the moment, since there are no standard protocols available, each firm adopts its own standards. This could create inconsistencies in the model, which if not properly detected, could lead to inaccurate and inconsistent BIM model. The project team should perform frequent "model audits" to ensure avoidance of any such issues (Weygant, 2011).

The interoperability issues, though significantly reduced during the last 5 years, still pose considerable risk. Interoperability is the ability to exchange data between applications to facilitate automation and avoidance of data re-entry. The introduction of Industry Foundation Classes (IFC) and XML Schemas has significantly helped to solve interoperability issues (Smith and Tardif, 2009). However, both of these approaches have their inherent limitations. The users must research interoperability while selecting BIM software applications.

When project team members other than the owner and architect/engineer contribute data that are integrated into the building information model, licensing issues can arise. For example, equipment and material vendors offer designs associated with their products for the convenience of the lead designer in hopes of inducing the designer to specify the vendor's equipment. While this practice might be good for business, licensing issues can arise if the designs were not produced by a designer licensed in the location of the project (Thompson and Miner, 2007).

\section{Process-related Risks}

The process-related risks include legal, contractual and organizational risks. The first risk is the lack of determination of ownership of the BIM data and the need to protect it through copyright laws and other legal channels. For example, if the owner is paying for the design, then the owner may feel entitled to own it, but if team members are providing proprietary information for use on the project, their proprietary information needs to be protected as well. Thus, there is no simple answer to the question of data ownership; it requires a unique response for every project depending on the participants' needs. The goal is to avoid inhibitions or disincentives that discourage participants from fully realizing the model's potential (Thompson, 2001). To prevent disagreement over copyright issues, the best solution is to set forth in the contract documents ownership rights and responsibilities (Rosenberg, 2007).

Another contractual issue to address is who will control the entry of data into the model and be responsible for any inaccuracies. Taking responsibility for updating building information model data and ensuring its accuracy entails a great deal of risk. Requests for complicated indemnities by BIM users and the offer of limited warranties and disclaimers of liability by designers are essential negotiation points that need to be resolved before BIM technology is used. It also requires more time spent inputting and reviewing BIM data, which is a new cost in the design and project administration process. Although these new costs may be dramatically offset by efficiency and schedule gains, they are still a cost that someone on the project team will incur. Thus, before BIM technology can be fully used, not only must the 
risks of its use be identified and allocated, but the cost of its implementation must be paid for as well (Thompson and Miner, 2007).

The integrated concept of BIM blurs the level of responsibility so much that risk and liability are likely to be enhanced. Consider the scenario in which the owner of the building files suit over a perceived design error. The architect, engineers, and other contributors to the BIM process look to each other in an effort to try to determine who had responsibility for the matter raised. If disagreement ensues, the lead professional not only will be responsible as a matter of law to the claimant but may have difficulty proving fault with others such as the engineers (Rosenberg, 2007).

One of the most effective ways to deal with such risks is to have collaborative, integrated project delivery contracts in which the risks of using BIM are shared among the project participants along with the rewards. Recently, the American Institute of Architects released an exhibit on BIM to help project participants define their BIM development plan for integrated project delivery (Building Design and Construction, 2008). This exhibit may assist project participants in defining model management arrangements, as well as authorship, ownership, and level-of-development requirements, at various project phases.

Based on a survey of 31 contracting firms in the United States, Ku and Taiebat (2011) found the following barriers to BIM implementation:

1. Learning curve and lack of skilled personnel

2. High cost to implementation

3. Reluctance of other stakeholders (e.g. architect, engineer, contractor)

4. Lack of collaborative work processes and modeling standards

5. Interoperability

6. Lack of legal/contractual agreements

They indicated that the advances in BIM technology, adoption of IPD and similar project delivery systems, requirement of BIM model by project owners, and introduction of fresh graduates with BIM knowledge in the project teams will ultimately help to avoid these barriers.

\section{Authors' Analysis and Conclusions}

BIM has changed the way the buildings are designed, constructed and operated. The use of BIM has led to improved profitability, reduced costs, better time management and improved customer-client relationships. BIM represents a new paradigm within AEC, one that encourages integration of the roles of all stakeholders on a project. This integration has brought greater efficiency and harmony among players who all too often in the past saw themselves as adversaries.

The successful implementation of BIM had allowed project stakeholders to re-engineer and streamline their processes to take full advantage of BIM. BIM has allowed implementing manufacturing concepts such as lean design and modularization into construction. The reemergence of modular construction as a "new" trend can be tied to the rise of BIM, as reported in the SmartMarket report of 2011 published by the McGraw-Hill Construction (SmartMarket Report, 2011). BIM is helping to make the fabrication of increasingly complex building assemblies and subassemblies economically and technologically feasible.

The way the BIM movement is progressing, it is not very far that BIM will completely replace CAD systems. As the market continues to adopt BIM as a standard, BIM will continue to flourish. The advances in smartphone and tablet technologies will allow users to instantly use BIM models for communications and quick decision-making. As the use of Cloud 
technology is growing, it would be easier for project stakeholders to quickly access BIM model virtually everywhere. The developments in augmented reality and similar virtual technologies will allow project owners and facility managers to more efficiently operate their buildings.

However, there are several technological and managerial challenges ahead. The technological challenges can be broadly classified into three categories (Azhar, 2011): (1) The need for well-defined transactional construction process models to eliminate data interoperability issues; (2) The requirement that digital design data be computable; and (3) The need for well-developed practical strategies for the purposeful exchange and integration of meaningful information among the building information model components.

The management challenges cluster around the implementation and use of BIM. Right now, there is no clear consensus on how to implement or use BIM. Unlike many other construction practices, there is no single BIM document providing instruction on its application and use (Associated General Contractors of America 2005). Furthermore, little progress has been made in establishing model BIM contract documents (Post, 2009). Several software firms are cashing in on the "buzz" of BIM and have programs to address certain quantitative aspects of it, but they do not treat the process as a whole. There is a need to standardize the BIM process and to define the guidelines for its implementation. Another contentious issue among the AEC industry stakeholders (i.e., owners, designers, and constructors) is who should develop and operate the building information models and how the developmental and operational costs should be distributed.

To optimize BIM performance, either companies or vendors, or both, will have to find a way to lessen the learning curve of BIM trainees. Software vendors have a larger hurdle of producing a quality product that customers will find reliable and manageable and that will meet the expectations set by the advertisements. Additionally, the industry will have to develop acceptable processes and policies that promote BIM use and govern today's issues of ownership and risk management (Post, 2009).

Researchers and practitioners have to develop suitable solutions to overcome these challenges and other associated risks. As a number of researchers, practitioners, software vendors, and professional organizations are working hard to resolve these challenges, the future of BIM is exciting and promising.

\section{Acknowledgements}

The authors would like to express their gratitude to Holder Construction Company, Atlanta, Georgia, USA for providing necessary data and photos. The first author of this paper is also indebted to School of Property, Construction and Project Management for providing travel funds to visit RMIT University and discuss BIM benefits and implementation challenges with Australian colleagues.

\section{References}

Associated General Contractors of America (2005) The Contractor's Guide to BIM, $1^{\text {st }}$ ed, AGC Research Foundation, Las Vegas, NV

Autodesk, Inc. (2008) Improving Building Industry Results through Integrated Project Delivery and Building Information Modeling

online at http://images.autodesk.com/adsk/files/bim and ipd whitepaper.pdf

Azhar, S., Behringer, A., Sattineni, A. and Mqsood, T. (2012) 'BIM for Facilitating Construction Safety Planning and Management at Jobsites', Accepted for publication in the Proceedings of the CIB-W099 International Conference: Modelling and Building Safety, Singapore, September 10-11, 2012 
Azhar, S. (2011) 'Building Information Modeling (BIM): Trends, Benefits, Risks and Challenges for the AEC Industry', ASCE Journal of Leadership and Management in Engineering, 11 (3), 241-252

Azhar, S., Carlton, W. A., Olsen, D, and Ahmad, I. (2011) 'Building Information Modeling for Sustainable Design and LEED ${ }^{\circledR}$ Rating Analysis', Journal of Automation in Construction (Special Issue on Building Information Modeling and Changing Construction Practices), 20 (2), 217-224

Azhar, S., and Richter, S. (2009) 'Building Information Modeling (BIM): Case Studies and Return-on-Investment Analysis', Proceedings of the Fifth International Conference on Construction in the 21st Century (CITC-V), Istanbul, Turkey, 1378-1386

Azhar, S., Hein, M., and Sketo, B. (2008a) 'Building Information Modeling: Benefits, Risks and Challenges', Proceedings of the 44th ASC National Conference, Auburn, AL, April 2-5

Azhar, S., Nadeem, A., Mok, J.Y.N., and Leung, B.H.Y. (2008b) 'Building Information Modeling (BIM): A New Paradigm for Visual Interactive Modeling and Simulation for Construction Projects', Proceedings of the First International Conference on Construction in Developing Countries (ICCIDC-I), Karachi, Pakistan, August 4-5

Azhar, S., Brown, J., and Farooqui, R. (2009) 'BIM-based Sustainability Analysis: An Evaluation of Building Performance Analysis Software', Proceedings of the 45th Annual ASC Conference, Gainesville, FL, April 1-4, 2009

Berlo, L.V. and Laat, R.D. (2011) 'Integration of BIM and GIS: The Development of the City GML GeoBIM Extension', Advances in 3D Geo-Information Sciences, Kolbe, T. H., König, G. and Nagel, C. (Eds.), Springer

Building Design and Construction (2008) New AIA Documents include BIM Agreement and Two New IPD Contracts, online at http://www.bdcnetwork.com/article/CA6600255.html

Carmona, J. and Irwin, K. (2007) 'BIM: Who, What, How and Why', Building Operating Management, October 2007

CICRP (2009) BIM Project Execution Planning Guide, Ver 1.0, The Computer Integrated Construction Research Group, The Pennsylvania State University, PA

CRC Construction Innovation (2007) Adopting BIM for Facilities Management: Solutions for Managing the Sydney Opera House, Cooperative Research Center for Construction Innovation, Brisbane, Australia

Eastman, C, Teicholz, P., Sacks, R. and Liston, K. (2011) BIM Handbook: A Guide to Building Information Modeling for Owners, Managers, Designers, Engineers and Contractors, $2^{\text {nd }}$ ed., NY: John Wiley and Sons

Glick, S. and Guggemos, A. (2009) 'IPD and BIM: Benefits and Opportunities for Regulatory Agencies'. Proceedings of the 45th ASC National Conference, Gainesville, Florida, April 2-4

Hardin, B. (2009) BIM and Construction Management, Indianapolis: Wiley Publishing, IN

Isikdag, U., Underwood, J. and Aouad, G. (2008) 'An investigation into the applicability of building information models in geospatial environment in support of site selection and fire response management processes', Advanced engineering informatics, 22, 504-519

Jordani, M. (2010) 'BIM and FM: The Portal to Lifecycle Facility Management', Journal for Building Information Modeling, Spring 2010, 13-16

Joyce, E. (2012) 'Augmented Reality for Facilities Management Edges Closer to Real-World Applications', Engineering News Record, April 9, 2012

Ku, K. and Taiebat, M. (2011) 'BIM Experiences and Expectations: The Constructor's Perspective', International Journal of Construction Education and Research, 7 (3), 175-197

Kymmell, W. (2008) Building Information Modeling: Planning and Managing Projects with 4D CAD and Simulations, USA:McGraw Hill Construction 
McGraw-Hill Construction (2008) Building Information Modeling: Transforming Design and Construction to Achieve Greater Industry Productivity, McGraw-Hill Construction, New York

NBIMS (2010) National Building Information Modeling Standard, online at http://www.wbdg.org/pdfs/NBIMSv1 p1.pdf

Newton, R. S. (2004) 'Inadequate Interoperability in Construction Wastes 415.8 Billion', AECNews.com, 13, Article 342

Philips, S. and Azhar, S. (2011) 'Role of BIM for Facility Management in Academic Institutions', Proceedings of the 6th International Conference on Construction in the 21st Century (CITC-VI), Kuala Lumpur, Malaysia, July 5-7, 950-957

Post, N. (2009) 'Building Team Members See Progress and Problems', Engineering NewsRecord, 22 (12), 28

Reddy, K. P. (2011) BIM for Building Owners and Developers, NJ: John Wiley and Sons

Rosenburg, T.L. (2007) Building Information Modeling, online at http://www.ralaw.com/resources/documents/Building\%20Information\%20Modeling\%20\%20Rosenberg.pdf

Rubenstone, J. (2012) 'Autodesk Steers Users Toward the Cloud With Expanded Subscription-based Services', Engineering News Record, April 16, 2012

Schueter, A. and Thessling, F. (2008) 'Building Information Model based energy/exergy performance assessment in early design stages', Automation in Construction, 18 (2), 153163

SmartMarket Report (2011) Prefabrication and modularization: Increasing productivity in the construction industry', online at

http://www.modular.org/htmIPage.aspx?name=McGrawHill_Prefabrication, accessed April 16, 2012

Smith, D.K., and Tardif, M. (2009) Building Information Modeling: A Strategic Implementation Guide for Architects, Engineers, Constructors, and Real Estate Asset Managers, NJ: John Wiley and Sons

Stine, J.D. (2011) Design Integration Using Autodesk Revit ${ }^{\circledR}$ 2012, Mission, KS: SDC Publications

Thompson, D.B. (2001) 'e-Construction: Don't Get Soaked by the Next wave', The Construction Law Briefing Paper, online at http://www.minnlaw.com/Articles/68553.pdf

Thompson, D.B. and Miner, R.G. (2007) Building Information Modeling - BIM: Contractual Risks are Changing with Technology, online at http://www.aepronet.org/ge/no35.html

Weygant, R.S. (2011) BIM Content Development: Standards, Strategies and Best Practices, $\mathrm{NJ}$ : John Wiley and Sons 